\title{
Differential Behavioral Effects of Plasma Tryptophan Depletion and Loading in Aggressive and Nonaggressive Men
}

James M. Bjork, Ph.D., Donald M. Dougherty, Ph.D., F. Gerard Moeller, M.D., and Alan C. Swann, M.D.

Preliminary findings indicate that men with high trait hostility may be prone to aggression increases following plasma tryptophan (Trp) depletion. We measured laboratory aggression in men selected for presence $(n=12)$ or absence $(n=12)$ of aggressive histories. Testing occurred before and after plasma Trp depletion, Trp loading, and under a food-restricted control condition. Subjects were provoked by subtractions of money, and aggression was measured as the responses the subject made to ostensibly subtract money from the instigator of the subtractions. When subjects were highly provoked, there was a significant Trp condition $\times$ aggression history interaction effect on aggressive responding. In particular, laboratory aggression in aggressive men was elevated under Trp-depleted conditions relative to Trp-loaded conditions, whereas the opposite occurred in nonaggressive men. Moreover, plasma total Trp levels after Trp loading were significantly higher in nonaggressive men, and plasma free (but not total) Trp levels after Trp loading correlated negatively with aggressive responses in the aggressive men. These data corroborate earlier findings that aggressive men may be more prone to aggression induced by reductions in plasma Trp. [Neuropsychopharmacology 22: 357-369, 2000] (C) 2000 American College of Neuropsychopharmacology. Published by Elsevier Science Inc.
KEY WORDS: Tryptophan; Tryptophan depletion; Serotonin; Aggression; Behavior

Substantial research has implicated decreased serotonin (5-HT) neurotransmission in human aggressive behavior (Brown et al. 1979; Coccaro et al. 1997a; Linnoila et al. 1983; Virkkunen et al. 1994). In recent neuroendocrine challenge studies, aggression has correlated negatively with plasma prolactin (PRL) elevations following the administration of the 5-HT agonist fenfluramine (Coccaro et al. 1996; Manuck et al. 1998). In another re-

From the Department of Psychiatry and Behavioral Sciences University of Texas-Houston Medical School, Houston, TX.

Address correspondence to: Donald M. Dougherty, Ph.D., Department of Psychiatry and Behavioral Sciences, University of TexasHouston Medical School, 1300 Moursund St., Houston, TX 77030; Email: ddoughrt@msi.uth.tmc.edu

Received June 15, 1999; revised October 12, 1999; accepted October 17, 1999 . cent report, PRL responses to both fenfluramine and $m$-CPP were blunted in personality-disordered individuals with high self-reported hostility (Coccaro et al. 1997a). Finally, other physiological responses to serotonergic agonists fenfluramine (Coccaro et al. 1996) and ipsapirone (Moeller et al. 1998) were inversely correlated with rates of laboratory aggression.

While these correlational data are compelling, the strongest support for the hypothesis that dysfunctional 5-HT neurotransmission facilitates aggression is prospectively-measured behavior change after the impairment or enhancement of the 5-HT system. This research in humans can be difficult in that serotonin-specific drugs can take days to weeks to exert any mood and/or behavior effects, and these effects may be too subtle for detection by many laboratory measures. Nevertheless, some data have shown a tendency for serotonergic drugs to decrease aggression in humans. For example, 
fluoxetine (Coccaro et al. 1997c) and sertraline (Kavoussi et al. 1994) attenuated clinician-rated impulsive aggression in psychiatric patients. Heiligenstein et al. (1993) meta-analyzed data from thousands of patients in several clinical trials of fluoxetine and found that aggressive acts were reported in only $0.15 \%$ of fluoxetinetreated patients, but $0.65 \%$ of placebo-treated patients. When aggression was measured prospectively, fluoxetine was effective in decreasing aggression in a psychiatric outpatients selected for prominent impulsive aggression (Coccaro and Kavoussi 1997).

The administration of a beverage of large neutral amino acids (LNAAs) which lacks 5-HT precursor L-tryptophan (Trp) can rapidly alter brain 5-HT (Young et al. 1985). This technique, called "tryptophan depletion," reduces brain Trp uptake in two ways: 1) LNAAs competitively inhibit active transport of Trp across the blood-brain barrier (Yuwiler et al. 1977), and 2) endogenous plasma Trp is incorporated into proteins in the hepatic response to the LNAA load (Gessa et al. 1975). Animal research has shown that Trp depletion dosedependently reduces brain levels of Trp, 5-HT, and the 5-HT metabolite 5-HIAA within a few hours (Biggio et al. 1974; Moja et al. 1989).

In humans, Trp depletion has decreased synthesis rates of a 5-HT analogue in the brain in a PET scanning experiment (Nishizawa et al. 1997), and has reduced cerebrospinal fluid concentrations of 5-HIAA (Carpenter et al. 1998; Williams et al. 1999). This restriction of Trp has been thought to decrease brain 5-HT through two mechanisms. First, Trp hydroxylase, the rate-limiting enzyme in 5-HT synthesis, is only half-saturated with Trp under normal physiological conditions (Young and Gauthier 1981). Therefore, changes in the availability of the Trp (substrate) can affect the ultimate rate of 5-HT synthesis. Second, newly synthesized cytoplasmic 5-HT (as opposed to vesicular 5-HT stores) may be the 5-HT which is preferentially released into the synapse to act on postsynaptic targets (Kuhn et al. 1985). This would explain why the acute restriction of 5HT synthesis by Trp depletion blunted the PRL response to fenfluramine in humans (Coccaro et al. 1998).

Trp depletion has worsened mood in persons prone to depression (Benkelfat et al. 1994; Menkes et al. 1994), especially in formerly-depressed subjects whose symptoms had remitted following the chronic administration of serotonergic antidepressants (Bremner et al. 1997; Delgado et al. 1990). Conversely, Trp depletion has not affected mood in several populations that were not characterized by mood symptomatology (e.g., Abbott et al. 1992; Benkelfat et al. 1994; Danjou et al. 1990; Ellenbogen et al. 1996; Oldman et al. 1994).

Trp depletion has also increased human laboratory aggression in designs when subjects were provoked (Bjork et al. 1999; Cleare and Bond 1995; Moeller et al. 1996; Pihl et al. 1995), but had no effect on the self- reported aggressiveness of unprovoked psychiatric patients (Salomon et al. 1994). Trp loading has shown some success, however, in decreasing aggression in psychiatric patients (Morand et al. 1983).

Just as depression risk may increase vulnerability to mood effects of Trp depletion, trait hostility may also confer a predisposition to aggression-promoting effects of Trp depletion. Cleare and Bond (1994) reported that increased self-reported aggressiveness following Trp depletion was specific to men scoring high on the Assault subscale of the Buss-Durkee Hostility Inventory (BDHI) (Buss and Durkee 1957). Hostile men also delivered more severe noise blasts to a fictitious antagonist under Trp-depleted conditions, whereas men selected for low trait hostility become more aggressive under Trp loaded conditions (Cleare and Bond 1995). Similarly, among the subjects in our earlier report (Bjork et al. 1999), the increased aggression under Trp-depleted conditions was specific to subjects scoring above the median score of the Buss-Perry Aggression Questionnaire (BPAQ) (Buss and Perry 1992).

The present study was designed to extend the findings of Cleare and Bond (1995) in men with and without significant histories of aggressive behavior. We recruited two groups of 12 men with high and low scores on the Life History of Aggression questionnaire (LHA; Coccaro et al. 1997b). In a within-subject design, the laboratory aggression of each subject was compared under conditions of Trp depletion, Trp loading, and foodrestriction alone. Within-subject aggression differences under Trp conditions were also compared between aggressive and nonaggressive groups. Aggression was in the form of money subtraction from a fictitious antagonist in the Point Subtraction Aggression Paradigm $(9$ (PSAP) (Cherek et al. 1997). The PSAP has been externally validated in several populations (Casat et al. 1995; Cherek et al. 1996 1997; Dougherty et al. 1999). We hypothesized that Trp depletion would increase laboratory aggression, but only in the group of men selected for aggressive histories.

Finally, we measured plasma cortisol concentrations to explore the role of 5-HT synthesis and transmission in the hypothalamic-pituitary-adrenal (HPA) stress response to provocation. In a recent report assessing neuroendocrine stress responses to PSAP provocation, men selected for aggressive or hostile personalities evidenced a robust cortisol response to money subtraction provocation in the PSAP, but nonaggressive men did not (Gerra et al. 1997). Evidence to date indicates that 5-HT modulates HPA activity by stimulating the HPA in the quiescent organism while blunting the HPA response to potent stressors. For example, 5-HT administered to PVN neurons in vitro stimulates corticotropinreleasing hormone (CRH) release (Fuller 1992; Jones et al. 1987), and Saphier and Feldman (1989) reported that stimulation of the dorsal raphe alone (in the absence of 
stress) excited paraventricular nucleus (PVN) neurons. Conversely, the HPA response to nonphysical stressors was blunted by peripheral Trp administration (Berger et al. 1974; Vernikos-Danellis et al. 1977) and by direct stimulation of the dorsal raphe (Kovacs et al. 1976). In humans, Trp depletion enhanced the HPA activation triggered by a pharmacological stressor (Koszycki et al. 1996). We therefore hypothesized that following high provocation, cortisol levels would be elevated in aggressive men, and this would be more robust under Trp-depleted conditions compared to Trp loading conditions.

\section{METHODS}

\section{Subject Recruitment}

All recruitment and study procedures were approved by the University of Texas-Houston Health Science Center Committee for the Protection of Human Subjects. Men age 18-40 were recruited by newspaper advertisement and notices posted at the Harris County Department of Corrections. No mention of aggression was made in any advertisements or in the interview. Callers underwent a brief phone interview to determine suitability for an on-site interview in the laboratory. Respondents who reported no medical conditions or recent drug use, and whose work schedule (if employed) did not conflict with weekday study participation were invited to visit the lab for an on-site interview. Subject characteristics are presented in Table 1.

\section{Psychometric Measures}

During the on-site interview, applicants underwent a Structured Clinical Interview for DSM-IV Axis I Disorders-Non-Patient version (SCID-NP) (First et al. 1996). Applicants who met criteria for a psychiatric disorder (including alcohol abuse/dependence or non-alcohol abuse/dependence) were excluded. Since histories of substance use are endemic among men with aggressive histories, applicants who were in full or partial remission of alcohol or non-alcohol use disorders were not excluded. Applicants who had a history of an Axis I disorder other than alcohol or non-alcohol substance use or dependence, however, were excluded from participation.

In addition, applicants were asked the diagnostic questions pertaining to conduct disorder (CD) and antisocial personality disorder (ASPD) contained in the Structured Clinical Interview for DSM-III-R Axis II Disorders (SCID-II) (Spitzer et al. 1990). Subjects completed other psychometric instruments during the interview to assess collateral between-group differences. These included the Beck Depression Inventory (BDI)- revised (Beck et al. 1979), the Beck Anxiety Inventory (BAI)
(Beck et al. 1988), the Barratt Impulsiveness Scale Version 11 (BIS-11) (Patton et al. 1995), and the Buss-Perry Aggression Questionnaire (BPAQ) (Buss and Perry 1992). Subjects also completed a medical questionnaire which was reviewed by an investigator to ensure absence of significant medical contraindications of participation, such as history of head injury.

\section{Group Selection}

Applicants were invited to participate if they scored either 20 or higher (aggressive group, $n=12$ ) or 9 or lower (nonaggressive group, $\mathrm{n}=12$ ) on the LHA. Intermediate scorers were excluded. These cutoff values were selected because they approximately demarcated the upper and lower quartiles of LHA scores in the men our laboratory typically recruits. The LHA is an interviewformat measure of the lifetime incidence of aggressive acts, such as: 1) physically assaulting someone, 2) arguing using loud voice, profanity and/or threats, 3) getting fired for being belligerent with a boss or supervisor, 4) getting suspended or expelled from school. The BPAQ was used as a corroborating measure for group selection. Specifically, a handful of applicants whose low LHA scores would have assigned them to the nonaggressive group but who had BPAQ (hostility) scores above the mean of 60.75 found in a previous male population (Bjork et al. 1999) were excluded. Similarly, applicants with aggressive histories but whose BPAQ score indicated a nonhostile personality $(<60.75)$ were also excluded.

\section{Behavioral Testing Apparatus}

The behavioral testing chamber was $1.8 \mathrm{~m} \times 1.8 \mathrm{~m} \times$ $2.2 \mathrm{~m}$ tall, and contained a countertop, a chair, and a ventilation fan which provided continuous masking noise. Each testing chamber also contained a 14" computer monitor and a response panel with buttons labeled " $A$ " and " $B$ " mounted in its top side. The response panel's connection wire was long enough for the subject to place it on his lap if desired. An IBM PC-compatible computer in an adjacent room controlled the experimental events using the PSAP software.

\section{Measurement of Aggression - the PSAP}

The PSAP (Cherek et al. 1996) measures the subject's aggressive response to the subtraction of "points" worth money the subject accumulated by repeatedly pressing a button (FR 100 schedule of reinforcement) in a 25-min testing session. Each subject was instructed that during each testing session, his console was connected to another console, which was ostensibly operated by another male participant in a different laboratory area (subject instructions appear verbatim in Bjork 
Table 1. Group Demographic and Psychometric Differences

\begin{tabular}{|c|c|c|c|}
\hline \multirow[b]{2}{*}{ Measure/parameter } & \multicolumn{2}{|c|}{ mean (SD) } & \multirow[b]{2}{*}{$\begin{array}{c}t \text {-test } \\
p \text {-value }\end{array}$} \\
\hline & $\begin{array}{l}\text { Aggressive } \\
\text { group } \\
(n=12)\end{array}$ & $\begin{array}{c}\text { Nonaggressive } \\
\text { group } \\
(\mathrm{n}=12)\end{array}$ & \\
\hline Age & $27.9(8.3)$ & $31.1(7.1)$ & .326 \\
\hline Weight (in kg) & $78.6(13.0)$ & $86.4(18.8)$ & .261 \\
\hline Education (in years) & $11.6(0.5)$ & $13.4(0.9)$ & .107 \\
\hline Race $^{*}$ & $\mathrm{aa}=8, \mathrm{c}=1, \mathrm{~h}=3$ & $\mathrm{aa}=8, \mathrm{c}=3, \mathrm{~h}=1$ & - \\
\hline \multicolumn{4}{|l|}{ Barratt Impulsiveness Scale } \\
\hline total score & $67.2(7.1)$ & $55.7(9.8)$ & .003 \\
\hline motor subscale & $24.9(4.9)$ & $20.2(4.0)$ & .020 \\
\hline attentional subscale & $17.8(3.4)$ & $13.5(4.8)$ & .021 \\
\hline non-planning subscale & $24.7(4.0)$ & $21.5(5.1)$ & .105 \\
\hline Beck Depression Inventory & $13.0(6.6)$ & $3.3(3.7)$ & .0002 \\
\hline Beck Anxiety Inventory & $13.1(7.3)$ & $3.0(3.0)$ & .0002 \\
\hline \multicolumn{4}{|l|}{ Buss-Perry Aggression Questionnaire } \\
\hline total score & $90.8(10.4)$ & $42.6(6.9)$ & .0001 \\
\hline physical subscale & $27.6(5.1)$ & $12.8(3.6)$ & .0001 \\
\hline hostility subscale & $25.3(5.2)$ & $11.5(2.9)$ & .0001 \\
\hline anger subscale & $20.3(4.5)$ & $9.8(2.0)$ & .0001 \\
\hline verbal subscale & $16.7(3.1)$ & $9.1(3.7)$ & .0001 \\
\hline Life History of Aggression & $28.5(6.7)$ & $4.8(2.6)$ & .0001 \\
\hline Alcohol use disorder in remission & $\mathrm{n}=4$ & $\mathrm{n}=2$ & - \\
\hline Drug use disorder in remission & $\mathrm{n}=3$ & $\mathrm{n}=0$ & - \\
\hline
\end{tabular}

and Dougherty 1998). He was instructed that the goal of the "physical performance task" was to earn as many points as possible, because his points were exchangeable for money. He was instructed that every 100 presses of the " $\mathrm{A}$ " button would advance the money counter displayed on his screen by $20 \notin$ (the moneyearning response), and that every 10 presses of the " $\mathrm{B}$ " button would subtract $20 \notin$ from the counter of the (fictitious) other participant (the aggressive response).

During testing, the subject experienced a subtraction of $20 \phi$ from his counter every 6-120 s. This was signaled by his money counter flashing for $2 \mathrm{~s}$ prior to the deduction of $20 \notin$. This money subtraction was blamed on the responding of the fictitious other participant. The subject was instructed that any points subtracted from his counter would be added to the other participant's counter, but points he subtracted from his opponent's counter by using his " $\mathrm{B}$ " button would not be added to his counter. This explained why the subject might experience point subtractions by another participant, but prevented the subject from aggressive responding to earn money on an easier reinforcement (FR10) schedule.

By completing the ratio requirement of button B (10 presses) after a money subtraction, the subject would initiate a provocation-free interval (PFI) lasting $500 \mathrm{~s}$, during which he or she did not experience any money subtractions. After the PFI had expired, the randominterval (6-120 s) money subtractions resumed. Aggressive responses after a PFI had been initiated but before the next money subtraction were counted but had no effect. Therefore, the subject was unable to avoid all provocation. Subjects typically aggressively respond to a money subtraction, reducing the number of money subtractions they experience in a single session from as many as 22 to as few as three with a 500 s PFI setting.

To verify the experimental deception, each subject completed a questionnaire at the end of the testing sessions each day, on which he described the "other person or persons" and estimated who took more points: himself, or the "other person or persons." Subjects whose responses indicated belief that their points were subtracted by a computer or the investigator were removed from the study and replaced.

\section{Study Schedule}

Subjects participated for five days, from 8:00 A.M. to 4:30 P.M. The first two days served as a baseline. On the latter three days, subjects were tested under each of Trp depleted $(\mathrm{T}-)$, Trp-loaded $(\mathrm{T}+)$, and food-restricted (FR) conditions (fasting with no AA drink). Two subjects from each of the two aggression groups were assigned to each of the six possible condition orders. Subjects did not return to the lab for at least $48 \mathrm{~h}$ following $\mathrm{T}-$ and $\mathrm{T}+$ conditions to allow plasma Trp to return to baseline levels.

Upon arrival each day, the subjects' breath alcohol was measured using Alco-Sensor III ${ }^{\circledR}$ breathalyzer (Intoximeters, Inc; St. Louis, MO), and urine samples were 
screened for the presence of cocaine and marijuana metabolites using the Syva ${ }^{\circledR}$ RapidTest d.a.u. urinalysis kit (Behring Diagnostics Inc; Cupertino, CA). Subjects whose breath alcohol level was above zero were dismissed for the day, and subjects whose urine tested positive for cocaine and/or marijuana were removed from the study.

Subjects then underwent PSAP testing four times across the day, corresponding to: $0 \mathrm{~h}$ post-drink $(0900 \mathrm{~h})$, $3 \mathrm{~h}$ post-drink $(1200 \mathrm{~h}), 5 \mathrm{~h}$ post drink $(1400 \mathrm{~h})$, and $6.75 \mathrm{~h}$ post-drink $(1545 \mathrm{~h})$. The time course of plasma Trp depletion indicates that plasma Trp reductions are still minimal $1 \mathrm{~h}$ after $\mathrm{T}-$ beverage ingestion, but are maximal 5-7 hours after T- ingestion (Delgado et al. 1990; Krahn et al. 1996).

Between sessions, subjects rested in a TV lounge, but smoking was not allowed. During breaks, subjects occasionally performed some unrelated tasks and questionnaires (these pilot data do not pertain to aggression and are not presented). During the PSAP sessions scheduled at $1545 \mathrm{~h}$, the PFI induced by aggressive responding to money subtractions was reduced from the normal $500 \mathrm{~s}$ to $125 \mathrm{~s}$. This reduction roughly doubles the number of money subtractions subjects experience (Bjork et al. 1999), and was scheduled to coincide with maximal Trp depletion on the $\mathrm{T}-$ drink ingestion day.

\section{Plasma Trp Manipulations}

At the conclusion of the second baseline day (Day 2), subjects received a low-monoamine diet instruction sheet, and were instructed to fast overnight before coming into the lab for testing for the remainder of the study (Days 3-5), when subjects experienced the three treatment conditions $(\mathrm{T}-, \mathrm{T}+$, and FR). These conditions were implemented to maximize the pharmacological impact of the T-drink, since plasma Trp concentrations in men reach their lowest circadian level in the morning after an overnight fast (Wurtman et al. 1968). We note, however, that the effects of the $\mathrm{T}+$ and $\mathrm{T}-$ drinks on plasma Trp/LNAA ratios are substantial relative to normal (dietary) variations. On the $\mathrm{T}-$ and $\mathrm{T}+$ condition days, AA drinks were administered under the supervision of a research assistant at $0850 \mathrm{~h}$.

The $100 \mathrm{~g}$ Trp-depleting $(\mathrm{T}-)$ drink used in this study has been a standard dose in studies with male subjects (Bjork et al. 1999; Delgado et al. 1990; Moeller et al. 1996; Pihl et al. 1995; Salomon et al. 1994; Young et al. 1988) and consisted of the following quantities of AAs partially dissolved in $350 \mathrm{ml}$ water: $5.5 \mathrm{~g}$ L-alanine, $4.9 \mathrm{~g}$ L-arginine, $3.2 \mathrm{~g}$ Glycine, $3.2 \mathrm{~g}$ L-histidine, $8.0 \mathrm{~g}$ L-isoleucine, $13.5 \mathrm{~g}$ L-leucine, $11.0 \mathrm{~g}$ L-lysine monohydrochloride, $5.7 \mathrm{~g}$ L-phenylalanine, $12.2 \mathrm{~g}$ L-proline, 6.9 g L-serine, $6.5 \mathrm{~g}$ L-threonine, $6.9 \mathrm{~g}$ L-tyrosine, and $8.9 \mathrm{~g}$ $\mathrm{L}$-valine. This aqueous suspension was flavored with 10 $\mathrm{ml}$ chocolate syrup and three drops of peppermint oil.
In addition, $2.7 \mathrm{~g}$ L-cysteine and $3.0 \mathrm{~g}$ L-methionine were administered in nine capsules along with each of the $\mathrm{T}+$ and $\mathrm{T}-$ drinks due to their unpalatability in the beverage. The $\mathrm{T}+$ drink consisted of the same mixture of the 15 AAs, but with the addition of $10.3 \mathrm{~g}$ L-tryptophan mixed into the drink. The $\mathrm{T}+$ drink has resulted in highly elevated serum tryptophan levels (Cleare and Bond 1995), and bolus doses of Trp have resulted in increased levels of CSF 5-HT metabolite (Young and Gauthier 1981).

\section{Plasma Measurements}

Subjects underwent four venipunctures, each occurring within 5 minutes after completing the final PSAP session on: 1) the first baseline day, 2) the Trp depletion day, 3) the Trp loading day, and 4) the food-restricted day. The plasma was frozen at $-90 \mathrm{C}$ until a radioimmune assay (RIA) analysis of cortisol using the Coat-aCount ${ }^{\circledR}$ kit by Diagnostic Products Corporation (Los Angeles, CA). In addition, plasma free Trp concentrations were determined using high-performance liquid chromatography (HPLC) with electrochemical detection (Kilts et al. 1981), and total Trp levels were measured with HPLC with spectrophotometric detection in the method of Holmes (1988).

\section{Data Analysis}

Mixed-model, repeated-measures analyses of variance (ANOVAs) were used. For analysis of aggressive responding rates across time under low provocation conditions, the ANOVA included within-subject factors: Session ( 3 levels: baseline, $3 \mathrm{hr}$, and $5 \mathrm{~h}$ post) nested within Condition ( 3 levels: $\mathrm{T}-, \mathrm{T}+$, and FR), and one between-subject factor: Group (2 levels: aggressive and nonaggressive). For analysis of aggressive responding to high provocation, the ANOVA included only the within-subject factor of Condition (3 levels: T-, T+, and FR) and the between-subject factor: Group (2 levels: aggressive and nonaggressive). Where data sphericity assumptions for repeated-measures ANOVA are violated, Huynh-Feldt corrected (H-F) $p$ values are presented. Statistical significance is set at $p<.05$.

\section{RESULTS}

The cutoff values of the LHA and corroboration requirement of the BPAQ caused roughly half of applicants to be denied an offer to participate. Seven other subjects had been recruited but did not complete the study. Subjects were dismissed for having drug-positive urine samples $(\mathrm{n}=2)$, declining to consume the AA drink $(n=1)$, and disbelief in a fictitious opponent in the PSAP $(n=2)$. Two subjects dropped out for un- 
known reasons. All completed subjects wrote in a "Purpose of Experiment" exit questionnaire that they thought the study had to do with the effects of AA drinks on physical performance. No response mentioned aggression.

The two groups substantially differed in ways besides aggressive behavior histories (Table 1). First, the two groups differed in self-reported motor and attentional impulsiveness as well as symptomatology of depression and anxiety. Additionally, among the aggressive group, 10 subjects met DSM-III-R criteria for conduct disorder as adolescents and 9 met criteria for antisocial personality disorder as adults.

\section{Plasma Trp}

Plasma was drawn at $1615 \mathrm{~h}$ immediately following the last PSAP session on each of the first baseline, $\mathrm{T}-, \mathrm{T}+$, and FR testing days. This corresponded to $7.25 \mathrm{~h}$ after $\mathrm{T}-$ or $\mathrm{T}+$ beverage consumption. There was a highly significant (and expected) main effect of Trp condition $(F(3,66)=17.656$, H-F $p<.001)$ on free Trp levels (Figure 1). Six post-hoc pairwise comparisons indicated that plasma free Trp under each of the four conditions (Baseline, $\mathrm{FR}, \mathrm{T}+$, and $\mathrm{T}-$ ) were all significantly different from each other (all $p<.01$ ). The main effect of group $(F(1,22)=2.884, p=.104)$ and the group $\times$ session interaction $(F(3,66)=2.902$, H-F $p=.102)$ did not reach significance. Higher mean plasma Trp levels after Trp loading were evident in the nonaggressive subjects compared to aggressive subjects, but this also did not reach significance $(t(22)=1.703, p=.102)$. To further characterize the difference in post-loading Trp levels, we also measured total Trp in plasma collected after Trp loading. The group difference in total Trp levels after Trp loading was significant $(t(22)=2.553, p=.018)$. When the slightly lower mean weight of aggressive subjects was controlled for as a covariate, this increased the significance of the between-group difference in post-loading plasma total $\operatorname{Trp}$ concentration $(F(1,21)=$ $5.044, p=.004)$.

\section{PSAP Behavior under Low Provocation Conditions}

As seen in Figure 2, there were generally no effects of Trp condition on money-earning responding rates under low provocation conditions. The main effects of session/time $(F(2,44)=0.304, p=.739)$, and Trp condition $(F(2,44)=0.914, p=.409)$ were not significant, with a weak trend for more money-earning responses in the aggressive group $(F(1,22)=2.645, p=.118)$. While the session $\times$ group $(F(2,44)=0.001, p=.999)$ and session $\times$ condition $(F(4,88)=0.872$, H-F $p=.446)$ interactions were nonsignificant, there was a trend toward a $\operatorname{Trp}$ condition $\times$ group interaction $(F(2,44)=3.150, p=$ $.053)$, with slightly elevated rates of money-earning re-

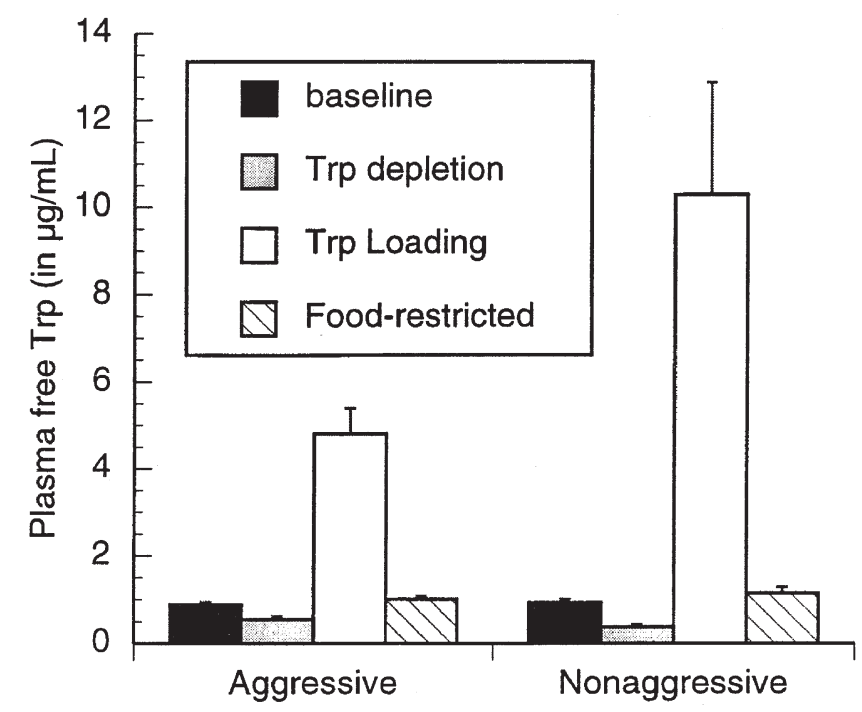

Figure 1. Mean ( \pm SEM) free Trp concentrations in plasma obtained at $1550 \mathrm{~h}$ (approximately $7.25 \mathrm{~h}$ after AA drink ingestion on the $\mathrm{T}-$ and $\mathrm{T}+$ protocol days).

sponses under food-restricted conditions in nonaggressive men. The group $\times$ session $\times$ condition interaction was not significant $(F(4,88)=0.619, p=.650)$.

There was also no effect of Trp condition on aggressive responding rates under low provocation conditions (Figure 3). The main effects of group $(F(1,22)=$ $0.237, p=.631)$, session/time $(F(2,44)=2.126$, H-F $p=$ $.150)$, and $\operatorname{Trp}$ condition $(F(2,44)=0.161, \mathrm{H}-\mathrm{F} p=.751)$ were not significant. None of the higher-order interaction effects was significant (session $\times$ group $F(2,44)=$ $0.157, \mathrm{H}-\mathrm{F} p=.773$; condition $\times$ group $F(2,44)=0.851$, $p=.441$; condition $\times$ session $F(4,88)=0.602, \mathrm{H}-\mathrm{F} p=$ .546 ; group $\times$ session $\times$ condition $F(4,88)=0.155, \mathrm{H}-\mathrm{F}$ $p=.849)$.

\section{PSAP Behavior under High Provocation Conditions}

Under the $\mathrm{T}-, \mathrm{T}+$, and FR conditions, the provocationfree interval (PFI) was reduced to $125 \mathrm{~s}$ in the final testing session which occurred $6.75 \mathrm{~h}$ after AA drink ingestion. This was to cause higher provocation frequency during peak Trp depletion.

There were no main effects of Trp condition $(F(2,44)=$ $0.224, p=.800)$ or group $(F(1,22)=0.354, p=.558)$ on money-earning responding under high provocation conditions (Figure 2, rightmost columns). The condition $\times$ group interaction was significant $(F(2,44)=6.106, p=$ $.005)$, however. While the groups produced nearly identical rates of amount of money-earning responses under $\mathrm{T}-(t(22)=0.092, p=.928)$ and FR $(t(22)=0.038, p=$ .970) conditions, aggressive subjects emitted slightly more money-earning responses under $\mathrm{T}+$ conditions 

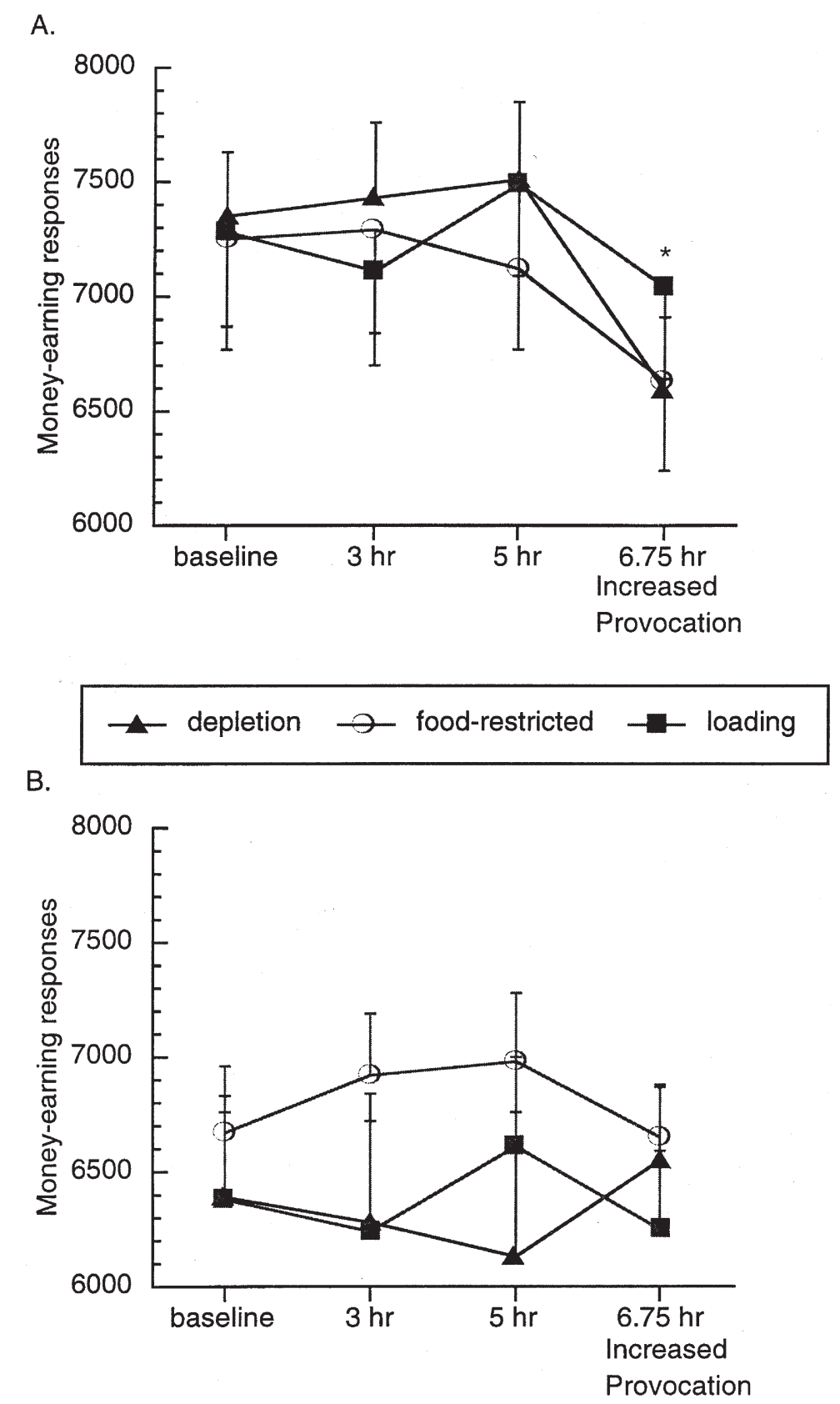

Figure 2. Money-earning behavior in PSAP sessions. Mean ( \pm SEM) rates of money-earning responses emitted by (A) aggressive and (B) nonaggressive subjects under $\mathrm{T}-, \mathrm{T}+$, and FR conditions. In the last session of each condition $(6.75 \mathrm{~h}$ post-drink), the provocation-free interval (PFI) was reduced to $125 \mathrm{~s}$ to increase provocation frequency. ${ }^{*}$ denotes a significant condition $\times$ group interaction in the high provocation testing sessions $(p<.05)$.

than nonaggressive subjects, but this was not significant $(t(22)=1.515, p=.144)$.

Increased provocation conditions, however, elicited significant effects of Trp condition on aggressive responding (Figure 3, rightmost columns). While there was no main effect of condition $(F(2,44)=0.150$, H-F $p=$ $.780)$ or group $(F(1,22)=0.521, p=.773)$ on aggressive responses, there was a significant condition $\times$ group interaction $(F(2,44)=4.701$, H-F $p=.028)$. This indicated that $\operatorname{Trp}$ depletion increased aggression relative to $\operatorname{Tr} p$ loading in aggressive men, but that the reverse was true in nonaggressive men. Across $\mathrm{T}-$ and $\mathrm{T}+$ conditions only, the condition $\times$ group interaction on aggressive responding rates was also significant $(F(1,22)=5.237$, $p=.032)$.

\section{Trp Loading and Aggression under High Provocation}

The group difference in the effects of the $\mathrm{T}+$ drink on aggressive responses under Trp-loaded conditions, 


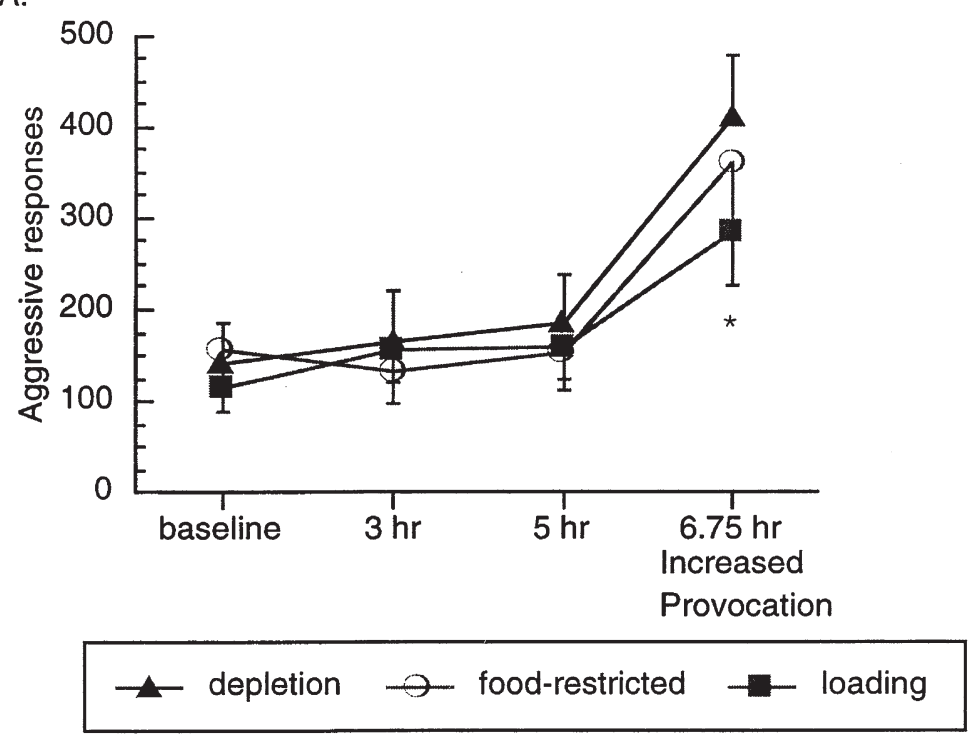

B.

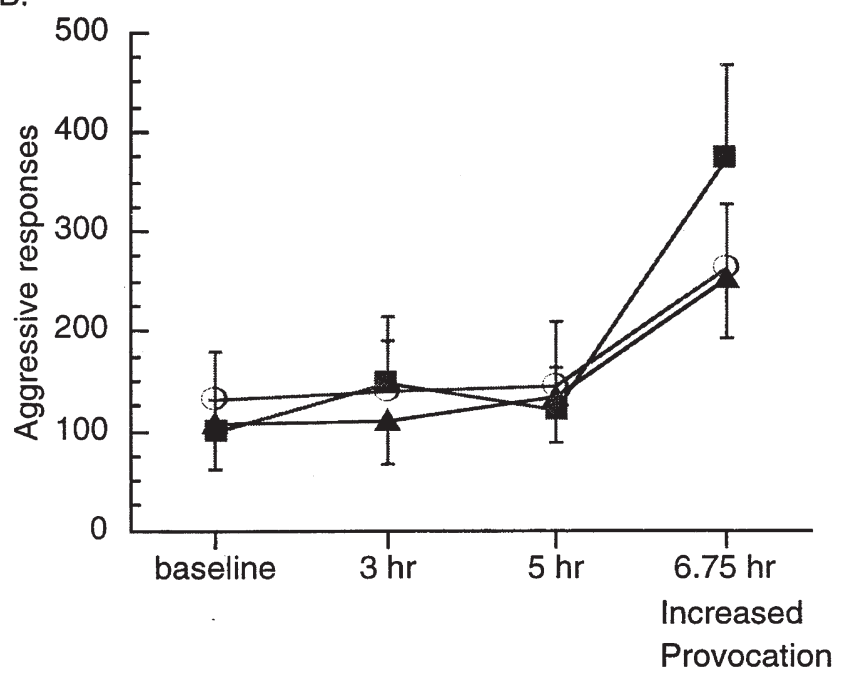

Figure 3. Aggressive behavior in PSAP sessions. Mean ( \pm SEM) rates of aggressive responses emitted by (A) aggressive and (B) nonaggressive subjects under $\mathrm{T}-, \mathrm{T}+$, and FR conditions. In the last session of each condition, the PFI was reduced to $125 \mathrm{~s}$ to increase provocation frequency. ${ }^{*}$ denotes a significant condition $\times$ group interaction in the high provocation testing sessions $(p<.05)$.

coupled with the group difference in plasma Trp levels remaining at that time point prompted us to determine whether plasma Trp levels directly related to aggressive responses just prior to the post-loading venipuncture. As shown in Figure 4, plasma free Trp concentrations of aggressive men following Trp loading inversely correlated with the number of aggressive responses they emitted in the high-provocation PSAP session immediately prior to that venipuncture (Spearman $\mathrm{r}=$ $-.619, p=.032)$. In Trp-loaded nonaggressive men, however, there was a tendency for aggressive responses to positively correlate with plasma Trp (Spearman $\mathrm{r}=$ $.548, p=.140)$. These correlations were significantly different from one another (Fisher Z-test $p<.02$ ) and were specific to aggressive responses in that money-earning responses in this PSAP session did not significantly correlate $(p>.25)$ with plasma Trp in either group of subjects. Correlations between plasma total Trp concentrations and aggressive responses in aggressive versus nonaggressive subjects showed the same opposing directions but these were not significant (Spearman $\mathrm{r}=$ $-.357, p=.255 ; \mathrm{r}=.354, p=.258$, respectively).

\section{Plasma Cortisol}

The average coefficient of variation (in \%) of gamma counts of the duplicate cortisol samples was $4.2 \%$. There were no appreciable main effects of the AA 
A.

Aggressive subjects

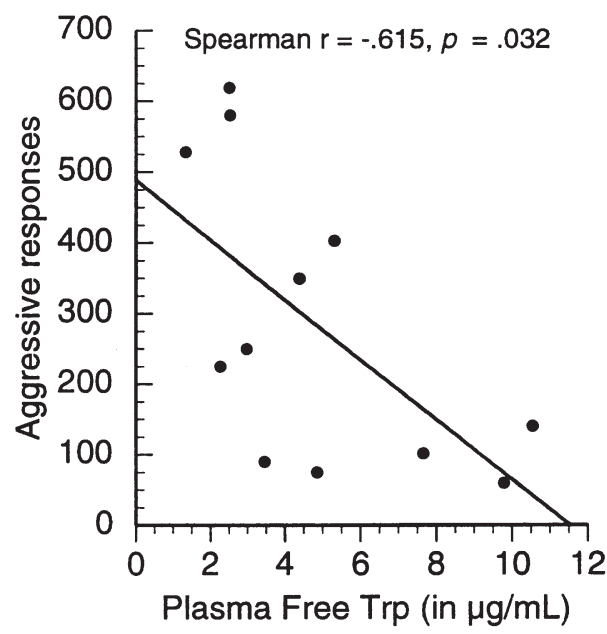

B. Nonaggressive subjects

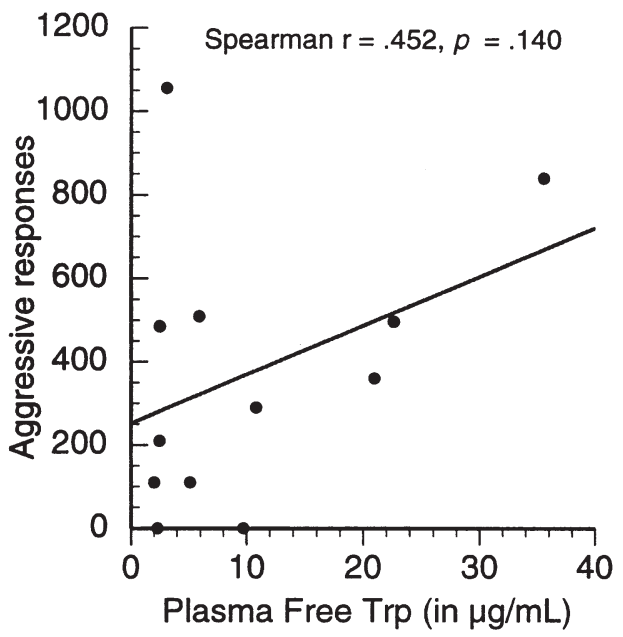

Figure 4. Correlations between plasma free Trp and PSAP aggression after Trp loading in (A) aggressive and (B) nonaggressive subjects. The PSAP session began $6.75 \mathrm{~h}$ after the $\mathrm{T}+$ drink, and plasma was drawn immediately after the session. The two correlations are significantly different from one another $(p<.05)$.

drinks or aggression history on cortisol levels. The results revealed no main effect of group $(F(1,22)=0.128$, $p=.724)$, Trp condition $(F(2,44)=0.296, p=.745)$, or group $\times$ condition interaction $(F(2,44)=2.166, p=.127)$.

\section{Post-hoc Analyses}

An unexpected finding was that $7.25 \mathrm{~h}$ after $\mathrm{T}+$ administration, plasma Trp levels remained almost twice as high in nonaggressive men as in aggressive men. An oral Trp load results in peak plasma concentrations only 1-3 h after Trp administration (Green et al. 1980; Holmes 1988; Moeller et al. 1996), with concentrations promptly descending to baseline levels. Therefore, the venipuncture most likely occurred during the descending arm of the plasma Trp concentration curve, such that the group difference likely arose from differences in hepatic metabolism of the Trp load.

Medical questionnaire responses of aggressive subjects indicated heavy drinking, even though none currently met DSM-IV criteria for alcohol abuse or dependence. To assess possible hepatic differences, baseline plasma samples were sent to a reference clinical pathology laboratory (LabCorp; Houston, TX) for a hepatic function profile. Results indicated only two instances of a liver enzyme above the normal range, and these elevations were slight. There were no significant differences in AST (SGOT), ALT (SGPT), or GGT between groups, and liver enzyme levels did not significantly correlate with post-loading free and total Trp values.

\section{DISCUSSION}

Under high provocation conditions, the hypothesized group-specific effect of Trp depletion on aggression was detected. Namely, aggression was increased under $\mathrm{T}-$ conditions relative to $\mathrm{T}+$ conditions in aggressive men, but the reverse was true in nonaggressive men. Moreover, in the aggressive men, aggressive responses under Trp-loaded conditions correlated negatively with plasma concentrations of free (but not total) Trp. This reflects PET scan findings in monkeys that rates of brain 5-HT (analogue) synthesis correlate with plasma concentrations of free Trp but not total Trp (Shoaf et al. 1998). Conversely, in nonaggressive men (who attained higher plasma Trp concentrations), post-loading plasma Trp tended to show a positive relationship with aggression. This group-specific reduction in aggression after plasma Trp loading reflects earlier findings of increased aggression-reducing effects of 5-HT agonists in dominant, as opposed to nondominant primates, (Raleigh et al. 1985).

Moreover, these results are in close agreement with two studies by Cleare and Bond (1994, 1995). The former study found that feelings of discontent after Tdrink ingestion worsened only in hostile men. The second study found that only men selected for scoring high on the Buss-Durkee Hostility Inventory (Buss and Durkee 1957) were more aggressive under T- conditions. In contrast, nonhostile men reported greater feelings of discontent after drinking the $\mathrm{T}+$ drink, and set a greater volume of noise blast for their fictitious opponent than they did under $\mathrm{T}-$ conditions. 
Trp depletion had no effect on aggressive behavior under low provocation conditions in either group. These findings differ from those previously obtained in this laboratory (Bjork et al. 1999; Moeller et al. 1996), which showed that aggressive responding rates significantly increased across the day after Trp depletion compared to control conditions. The present results may have arisen from the subject compensation conditions. In our previous study (Bjork et al. 1999), money earned in the PSAP sessions provided the sole compensation. Here, additional compensation had been given to the subjects for performing other tasks during breaks between the PSAP sessions as well as a bonus for finishing the study. Therefore, the handful of money subtractions (usually 3 or 4) experienced in these PSAP sessions represented a smaller proportional loss of participation earnings.

Indeed, previous research suggests that a threshold of provocation exists for detecting a Trp depletion effect on aggressive behavior (Chamberlain et al. 1987). For example, psychiatric inpatients selected for aggressiveness did not show any worsening of aggressive feelings after ingesting a $\mathrm{T}-$ drink under conditions with no provocation (Salomon et al. 1994). Similarly, male controls did not select higher shocks in the Buss (1961) teacher-learner aggression model under $\mathrm{T}-$ conditions when they were not directly provoked by the "learner" (Smith et al. 1986).

Cortisol levels following frequent money-subtraction provocation showed no significant group or dose differences. Subjects had already experienced several point subtractions in baseline PSAP sessions, and may have acclimated to them. Also, venipunctures performed immediately after the 25 min PSAP session may have missed peak elevations. Using indwelling catheters, Gerra et al. (1997) reported the greatest cortisol elevation $20 \mathrm{~min}$ into the testing session. Finally, the availability of an aggressive response which reduced subsequent provocation may have blunted the stressfulness of the point subtractions (Berkowitz and Embree 1987).

Given the predominance of data showing an inverse relationship between 5-HT functioning and aggressive behavior, findings that Trp loading increases aggression in nonaggressive controls are intriguing. Increased aggression by controls under $\mathrm{T}+$ conditions may have resulted from increased sensitivity to other (excitatory) Trp metabolites (reviewed in Stone (1993)). In contrast, aggressive behavior in aggressive men may be more sensitive to enhancements of the 5-HT system. For example, men with the worst 5-HT functioning as assessed in a neuroendocrine challenge showed the best improvement in aggressive symptoms after treatment with Fluoxetine (Coccaro et al. 1997c).

The $\mathrm{T}+$ drink is generally used as a control for the $\mathrm{T}$-drink under the assumption that it will affect brain function primarily by driving the brain 5-HT system forward. However, most dietary Trp is metabolized into the Kynurenine (Kyn) pathway and not into 5-HT (Stone and Connick 1985). In healthy men, plasma Kyn concentration has correlated with severity of self-rated anxiety symptoms (Orlikov and Ryzov 1991). One Kyn metabolite, quinolinic acid (QA), is a selective NMDA receptor agonist (reviewed in Freese et al. (1990)), and a monoamine oxidase-B (MAO-B) inhibitor (Naoi et al. 1987). A peripherally-administered dose of Trp which less than doubled extracellular brain 5-HT in rats increased the brain QA concentration 80-fold (During et al. 1989), and QA has been shown to have stimulant (Lapin 1978) and anxiogenic (Lapin 1996) properties in animals. These data collectively suggest a potential for a large Trp bolus to alter behavior by: 1) heightened NMDA receptor activation, and 2) increased norepinephrine neurotransmission by inhibiting catecholamine elimination by MAO-B.

In conclusion, this experiment revealed significantly different effects of plasma Trp manipulations on aggressive behavior between men with and without trait aggressiveness. Moreover, aggressive men cleared the Trp bolus from plasma more readily than nonaggressive men. This raises the possibility that a difference in peripheral Trp metabolism may underlie the increased aggression of persons with indices of lower central 5-HT function. Future research on Trp depletion and aggression could incorporate concurrent measures of 5-HT functioning (such as neuroendocrine challenge) as a variable in the analysis of individual differences in aggression following plasma Trp perturbation.

\section{ACKNOWLEDGMENTS}

This experimental partially fulfilled the requirements for the doctoral degree of James M. Bjork from the University of Texas-Houston Graduate School of Biomedical Sciences. This research was primarily supported by a grant from the Harry Frank Guggenheim Foundation to Dr. Dougherty. Additional support was provided by the National Institute on Alcohol Abuse and Alcoholism (grants RO1-AA12046 to Dr. Dougherty and RO1-AA10828 to Dr. Moeller). The authors wish to thank Angela Hamilton, Dr. Chester Davis for his assistance in the MSI Analytical Neurochemistry Laboratory, and Eleanor Dockery-Wade for phlebotomy services

\section{REFERENCES}

Abbott FV, Etienne P, Franklin KBJ, Morgan MJ, Sewitch MJ, Young SN (1992): Acute tryptophan depletion blocks morphine analgesia in the cold-pressor test in humans. Psychopharmacology 108:60-66

Beck AT, Rush AJ, Shaw BF, Emery G (1979): Cognitive Theory of Depression. New York: The Guilford Press

Beck AT, Brown G, Epstein N, Steer RA (1988): An inventory 
for measuring clinical anxiety: psychometric properties. J Consult Clin Psychol 56:893-897

Benkelfat C, Ellenbogen MA, Dean P, Palmour RM (1994): Mood-lowering effect of tryptophan depletion: Enhanced susceptibility in young men at genetic risk for major affective disorders. Arch Gen Psychiatry 51:687-697

Berger PA, Barchas PD, Vernikos-Danellis J (1974): Serotonin and pituitary-adrenal function. Nature 248:424-426

Berkowitz L, Embree MC (1987): The effect of escape possibility on aversively stmulated aggression. J Res Pers 21:405-416

Biggio G, Fadda F, Fanni P, Tagliamonte A, Gessa GL (1974): Rapid depletion of serum tryptophan, serotonin, and 5-hydroxyindoleacetic acid by a tryptophan-free diet. Life Sci 14:1321-1329

Bjork JM, Dougherty DM (1998): Differences in alcohol expectancy between aggressive and nonaggressive social drinkers. Alc Clin Exp Res 22:1943-1950

Bjork JM, Dougherty DM, Moeller FG, Cherek DR, Swann AC (1999). The effects of tryptophan depletion and loading on laboratory aggression in men: time course and a food-restricted control. Psychopharmacology 142:24-30

Bremner JD, Innis RB, Salamon RH, Staib LH, Ng CK, Miller HL, Bronen RA, Krystal JH, Duncan J, Rich D, Price LH, Malison R, Dey H, Soufer R, Charney DS (1997): Positron emission tomography measurement of cerebral metabolic correlates of tryptophan depletioninduced depressive relapse. Arch GenPsychiatry 54:364-374

Brown GL, Goodwin FK, Ballenger JC, Goyer PF, Major LF (1979): Aggression in humans correlates with cerebrospinal fluid amine metabolites. Psychiatry Res 1:131-139

Buss AH (1961) The Psychology of Aggression. New York, John Wiley \& Sons

Buss AH, Durkee A (1957): An inventory for assessing different kinds of hostility. J Consult Psychol 21:343-349

Buss AH, Perry M (1992): The Aggression Questionnaire. J Pers Soc Psychol 63:452-459

Carpenter LL, Anderson GA, Pelton GH, Gudin JA, Kirwin PDS, Price LH, Heninger GR, McDougal CJ (1998): Tryptophan depletion during continuous CSF sampling in healthy human subjects. Neuropsychopharmacology 19:26-35

Casat CD, Pearson DA, Van Davelaar MJ, Cherek DR (1995): Methylphenidate effects on a laboratory aggression measure in children with ADHD. Psychopharmacol Bull 31:353-356

Chamberlain B, Ervin FR, Pihl RO, Young SN (1987): The effect of raising or lowering tryptophan levels on aggression in vervet monkeys. Pharmacol Biochem Behav 28:503-510

Cherek DR, Schnapp W, Moeller FG, Dougherty DM (1996): Laboratory measures of aggressive responding in male parolees with violent and nonviolent histories. Aggressive Behavior 22:27-36

Cherek DR, Moeller FG, Schnapp W, Dougherty DM (1997): Studies of violent and nonviolent male parolees: I. Lab- oratory and psychometric measurements of aggression. Biol Psychiatry 41:514-522

Cleare AJ, Bond AJ (1994): Effects of alterations in plasma tryptophan levels on aggressive feelings. Arch Gen Psychiatry 51:1004-1005

Cleare AJ, Bond AJ (1995): The effect of tryptophan depletion and enhancement on subjective and behavioral aggression in normal male subjects. Psychopharmacology 118:72-81

Coccaro EF, Kavoussi RJ (1997): Fluoxetine and impulsive aggressive behavior in personality-disordered subjects. Arch Gen Psychiatry 54:1081-1088

Coccaro EF, Berman ME, Kavoussi RJ, Hauger RL (1996): Relationship of prolactin response to d-fenfluramine to behavioral and questionnaire assessments of aggression in personality-disordered men. Biol Psychiatry 40:157-164

Coccaro EF, Kavoussi RK, Trestman RL, Gabriel SM, Cooper TB, Siever LJ (1997a): Serotonin function in human subjects: intercorrelations among central 5-HT indices and aggressiveness. Psychiatry Res 73:1-14

Coccaro EF, Berman ME, Kavoussi RJ (1997b): Assessment of life history of aggression: development and psychometric characteristics. Psychiatry Res 73:147-157

Coccaro EF, Kavoussi RJ, Hauger RL (1997c): Serotonin function and antiaggressive response to fluoxetine: a pilot study. Biol Psychiatry 42:546-552

Coccaro EF, Kavoussi RJ, Cooper TB, Hauger R (1998): Acute tryptophan depletion attenuates the prolactin response to d-fenfluramine challenge in healthy human subjects. Psychopharmacology 138:9-15

Danjou P, Hamon M, Lacomblez L, Warot D, Kecskemeti S, Puech AJ (1990): Psychomotor, subjective and neuroendocrine effects of acute tryptophan depletion in the healthy volunteer. Psychiatry and Psychobiology 5:31-38

Delgado PL, Charney DS, Price LH, Aghajanian GK, Landis H, Heninger GR (1990): Serotonin function and the mechanism of antidepressant action: Reversal of antidepressant-induced remission by rapid depletion of plasma tryptophan. Arch Gen Psychiatry 47:411-418

Dougherty DM, Bjork JM, Huckabee HCG, Moeller FG, Swann AC (1999): Laboratory measures of aggression and impulsivity in women with borderline personality disorder. Psychiatry Res 85:315-326

During MJ, Freese A, Heyes MP (1989): Neuroactive metabolites of L-tryptophan, serotonin, and quinolinic acid, in striatal extracellular fluid: effect of tryptophan loading. FEBS Lett 247:438-444

Ellenbogen MA, Young SN, Dean P, Palmour RM, Benkelfat C (1996): Mood response to acute tryptophan depletion in healthy volunteers: Sex differences and temporal stability. Neuropsychopharmacology 15:465-474

First, MB, Spitzer RL, Gibbon, M, Williams JBW (1996): Structured Clinical Interview for DSM-IV Axis I Disorders: Non-patient Edition (SCID-NP). Biometrics Research Department, New York State Psychiatric Institute, NY

Freese A, Swartz KJ, During MJ, Martin JB (1990): Kynurenine metabolites of tryptophan: Implications for neurologic diseases. Neurology 40:691-695

Fuller RW (1992): The involvement of serotonin in regulation of pituitary-adrenocortical function. Frontiers in Neuroendocrinology 13:250-270 
Gerra G, Zaimovic A, Avanzini P, Chittolini B, Giucastro G, Caccavari R, Palladino M, Maestri D, Monica C, Delsignore R, Brambilla F (1997): Neurotransmitter-neuroendocrine responses to experimentally induced aggression in humans: influence of personality variable. Psychiatry Research 66:33-43

Gessa GL, Biggio G, Fadda F, Corsini GU, Tagliamonte A (1975): Tryptophan-free diet: A new means for rapidly decreasing brain tryptophan content and serotonin synthesis. Acta Vitaminol Enzymol 29:72-78

Green AR, Aronson JK, Curzon G, Woods HF (1980): Metabolism of an oral tryptophan load I: Effects of dose and pretreatment with tryptophan. Br J Clin Pharmacol 10:603-610

Heiligenstein JH, Beasley CM Jr, Potvin JH (1993): Fluoxetine not associated with increased aggression in controlled clinical trials. Int Clin Psychopharmacol 8:277-280

Holmes E (1988): Determination of serum kynurenine and hepatic tryptophan dioxygenase activity by high-performance liquid chromatography. Anal Biochem 172:518-525

Jones MT, Gillham B, Campbell EA, Al-Taher ARH, Chuang TT, DiSciullo A (1987): Pharmacology of neural pathways affecting CRH secretion. Annals of the New York Academy of Sciences 512:162-175

Kavoussi RJ, Liu J, Coccaro EF (1994): An open trial of sertraline in personality disordered patients with impulsive aggression. Journal of Clinical Psychiatry 55:137-141

Kilts CD, Breese GR, Mailman RB (1981): Simultaneous quantification of dopamine, 5-hydroxytryptamine and four metabolically related compounds by means of reversed-phase high-performance liquid chromatography with electrochemical detection. J Chromatogr 225:347-357

Koszycki D, Zacharko RM, LeMelledo J-M, Young SN, Bradwejn J (1996): Effect of acute tryptophan depletion on behavioral, cardiovascular, and hormonal sensitivity to cholecystokinin-tetrapeptide challenge in healthy volunteers. Biol Psychiatry 40:648-655

Kovacs GL, Kishonti J, Lissak K, Telegdy G (1976): Inhibitory action of midbrain raphe stimulation on stressinduced elevation of plasma corticosterone level in rats. Neuroscience Letters 3:305-310

Krahn LE, Yu PY, Klee G, Delgado PR, Lin S-C, Zimmermann RC (1996): Examining serotonin function: A modified technique for rapid tryptophan depletion. Neuropsychopharmacology 15:325-328

Kuhn DM, Wolf WA, Youdim MBH (1985): 5-hydroxytryptamine release in vivo from a cytoplasmic pool: studies on the 5-HT behavioral syndrome in reserpinized rats. Br J Pharmacol 84:121-129

Lapin IP (1978): Stimulant and convulsive effects of kynurenines injected into brain ventricles in mice. J Neural Transm 42:37-43

Lapin IP (1996): Kynurenines and anxiety. Adv Exp Med Biol 398:191-194

Linnoila M, Virkkunen M, Scheinin M, Nuutila A, Rimon R, Goodwin FK (1983): Low cerebrospinal fluid 5-hydroxyindoleacetic acid concentration differentiates impulsive from nonimpulsive violent behavior. Life Sci 33:26092614
Manuck SB, Flory JD, McCaffrey JM, Matthews KA, Mann JJ, Muldoon MF (1998): Aggression, impulsivity, and central nervous system serotonergic responsivity in a nonpatient sample. Neuropsychopharmacology 19:287-299

Menkes DB, Coates DC, Fawcett JP (1994): Acute tryptophan depletion aggravates premenstrual syndrome. J Affect Disord 32:37-44

Moeller FG, Dougherty DM, Swann AC, Collins D, Davis CM, Cherek DR (1996): Tryptophan depletion and aggressive responding in healthy males. Psychopharmacology 126:97-103

Moeller FG, Allen T, Cherek DR, Dougherty DM, Lane S, Swann AC (1998): Ipsapirone neuroendocrine challenge: relationship to aggression as measured in the human laboratory. Psychiatry Res 81:31-38

Moja EA, Cipolla P, Castoldi D, Tofanetti O (1989): Doseresponse decrease in plasma tryptophan and in brain tryptophan and serotonin after tryptophan-free amino acid mixtures in rats. Life Sci 44:971-976

Morand C, Young SN, Ervin FR (1983): Clinical response of aggressive schizophrenics to oral tryptophan. Biol Psychiatry 18:575-578

Naoi M, Ishiki R, Nomura Y, Hasegawa S, Nagatsu T (1987): Quinolinic acid: an endogenous inhibitor specific for type B MAO in human brain synaptosomes. Neurosci Lett 74:232-236

Nishizawa S, Benkelfat C, Young SN, Leyton M, S Mzengeza, DeMontigny C, Blier P, Diksic M (1997): Differences between males and females in rates of serotonin synthesis in human brain. Proc Natl Acad Sci USA 94:5308-5313

Oldman AD, Walsh AES, Salkovskis P, Laver DA, \& Cowen PJ (1994): Effect of acute tryptophan depletion on mood and appetite in healthy volunteers. J Psychopharmacol 8:8-13

Orlikov A, Ryzov I (1991): Caffeine-induced anxiety and increase of kynurenine concetration in plasma of healthy subjects: a pilot study. Biol Psychiatry 29:391-396

Patton JH, Stanford MS, Barratt ES (1995): Factor structure of the Barratt Impulsiveness Scale. J Clin Psychol 51:768-774

Pihl RO, Young SN, Harden P, Plotnick S, Chamberlain B, Ervin, FR (1995): Acute effect of altered tryptophan levels and alcohol on aggression in normal human males. Psychopharmacology 119:353-360

Raleigh MJ, Brammer GL, McGuire MT, Yuwiler A (1985): Dominant social status facilitates the behavioral effects of serotonergic agonists. Brain Res 348:274-282

Salomon RM, Mazure CM, Delgado PL, Mendia P, Charney DS (1994): Serotonin function in aggression: The effect of acute tryptophan depletion in aggressive patients. Biol Psychiatry 35:570-572

Saphier D, Feldman S (1989): Paraventricular nucleus neuronal responses following electrical stimulation of the midbrain dorsal raphe: Evidence for cotransmission. Exp Brain Res 78:407-414

Shoaf SE, Carson R, Hommer D, Williams W, Higley JD, Schmall B, Herscovitch P, Eckelman E, Linnoila M (1998): Brain serotonin synthesis rates in rhesus monkeys as determined by 11-C-alpha-methyl-L-tryptophan and positron emission tomography compared to 
CSF 5-hydroxyindole-3-acetic acid concentrations. Neuropsychopharmacology 19:345-353

Smith SE, Pihl RO, Young SN, Ervin FR (1986): Elevation and reduction of plasma tryptophan and their effects on aggression and perceptual sensitivity in normal males. Aggressive Behavior 12:393-407

Spitzer RL, Williams JBW, Gibbon M, First MB (1990): Structured clinical interview for DSM-III-R. Washington: APA

Stone TW (1993): Neuropharmacology of Quinolinic and Kynurenic acids. Pharmacol Rev 45:309-379

Stone TW, Connick JH (1985): Quinolinic acid and other kynurenines in the central nervous system. Neuroscience 15:597-617

Vernikos-Danellis J, Kellar KJ, Kent D, Gonzales C, Berger PA, Barchas JD (1977): Serotonin involvement in pituitary-adrenal function. Ann NY Acad Sci 297:518-526

Virkkunen M, Kallio E, Rawlings R, Tokola R, Poland RE, Guidotti A, Nemeroff C, Bissette G, Kalogeras K, Karonen SL, Linnoila M (1994): Personality profiles and state aggressiveness in Finnish alcoholic, violent offenders, fire setters, and healthy volunteers. Arch Gen Psychiatry 51:28-33
Williams WA, Shoaf SE, Hommer D, Rawlings R, Linnoila M (1999): Effects of acute tryptophan depletion on plasma and cerebrospinal fluid tryptophan and 5-hydroxyindoleacetic acid in normal volunteers. J Neurochem 72:1641-1647

Wurtman RJ, Rose CM, Chou C, Larin FF (1968): Daily rhythms in the concentrations of various amino acids in human plasma. N Eng J Med 279:171-175

Young SN, Gauthier S (1981): Effect of tryptophan administration on tryptophan, 5-hydroxyindoleacetic acid, and indoleacetic acid in human lumbar and cisternal cerebrospinal fluid. J Neurol Neurosurg Psychiatry 44:323327

Young SN, Smith SE, Pihl RO, Ervin FR (1985): Tryptophan depletion causes a rapid lowering of mood in normal males. Psychopharmacology 87:173-177

Young SN, Pihl RO, Ervin FR (1988): The effect of altered tryptophan levels on mood and behavior in normal human males. Clin Neuropharmacol 11 (Suppl 1):S207-215

Yuwiler A, Oldendorf WH, Geller E, Braun L (1977): Effect of albumin binding and amino acid competition on tryprtophan uptake into brain. J Neurochem 28:10151023 